\title{
Halofuginone attenuates articular cartilage degeneration by inhibition of elevated TGF- $\beta 1$ signaling in articular cartilage in a rodent osteoarthritis model
}

\author{
WENBO MU ${ }^{1}$, BOYONG XU ${ }^{1}$, HAIRONG MA ${ }^{1,2}$, BAOCHAO JI ${ }^{1}$, \\ ZHENDONG ZHANG ${ }^{1}$, JIAO LI ${ }^{1}$, ABDUSAMI AMAT ${ }^{1}$ and LI CAO ${ }^{1}$ \\ Departments of ${ }^{1}$ Orthopaedics and ${ }^{2}$ Clinical Medical Research Institute, \\ First Affiliated Hospital of Xinjiang Medical University, Urumqi, Xinjiang 830054, P.R. China
}

Received January 24, 2017; Accepted August 14, 2017

DOI: $10.3892 / \mathrm{mmr} .2017 .7549$

\begin{abstract}
Osteoarthritis (OA) is the most common degenerative condition of the weight-bearing joints worldwide without effective medical therapy. In order to investigate whether administration of halofuginone (HF) may attenuate OA, the present study allocated 3-month-old male mice into Sham group, vehicle-treated anterior cruciate ligament transection (ACLT) group and HF-treated ACLT group. The present study determined that $\mathrm{HF}$ treatment reduced the expression of matrix metallopeptidase-13 and collagen $\mathrm{X}$ in articular cartilage. Additionally, it lowered the Osteoarthritis Research Society International-Modified Mankin score and prevented the loss of articular cartilage from Safranin $O$ and Fast Green staining. HF reduced the progression of osteoarthritis by downregulating abnormally elevated TGF- $\beta 1$ activity in articular cartilage. Administration of HF may be a potential preventive therapy for OA.
\end{abstract}

\section{Introduction}

Osteoarthritis (OA) is the most common type of arthritis, characterized by pain and loss of joint function (1). Knee joint OA has been reported to affect $3.64 \%$ of the population worldwide in 2010 (2). Currently, there is no effective disease-modifying therapy for OA. Pain management and joint replacement are the options for end-stage OA $(3,4)$. The pathogenesis of OA remains unclear and an improved understanding is required in order to target the prevention and effective intervention for early-stage OA (5).

Correspondence to: Dr Li Cao, Department of Orthopaedics, First Affiliated Hospital of Xinjiang Medical University, 137 South Liyushan Road, Urumqi, Xinjiang 830054, P.R. China

E-mail: xjbone@21cn.com

Key words: osteoarthritis, articular artilage, TGF- $\beta 1$, elevation, halofuginone
The transforming growth factor- $\beta$ (TGF- $\beta$ ) superfamily consists of $>35$ members, including TGF- $\beta 1$, activins and bone morphogenetic proteins (6). They have an active role in the development and homeostasis of various tissues. Previous in vivo and ex vivo studies have reported that TGF- $\beta 1$ is crucial for the formation of articular cartilage during development. It may increase the production of proteoglycan and collagen type II (Col II). Lack of TGF- $\beta 1$ may induce a normal joint into the OA-phenotype $(7,8)$. However, previous studies also determined that TGF- $\beta$ also exerts deleterious effect in adult joints. Massicotte et al noticed increased TGF- $\beta$ level in human osteoarthritic osteoblasts compared with normal cells (9). Additionally, high levels of TGF- $\beta$ were found in OA cartilage when compared with normal ones in humans (10). Moldovan et al reported that TGF- $\beta$ may lead to result elevated levels of matrix metallopeptidase (MMP)-13 in normal cartilage, which mimicked the in situ distribution that observed in arthritic cartilage (11). Multiple intra-articular injections of TGF- $\beta 1$ in normal adult mice joints may induce inflammation and osteophyte formation, leading to the onset of OA $(12,13)$.

Halofuginone (HF) is an analogue of febrifugine, which is an alkaloid originally isolated from the plant Dichroa febrifuga (14). HF is used in commercial poultry production worldwide (15). Increased attention has been paid to this small molecule for its beneficial biological activity. HF has been identified as crucial in dealing with fibrosis and fibroblasts to myofibroblasts transition by inhibiting SMAD family member $2 / 3(\operatorname{Smad} 2 / 3)$ phosphorylation downstream of the TGF- $\beta$ signaling pathway $(16,17)$. HF has been demonstrated to be effective in treating muscle fibrosis in Duchenne muscular dystrophy and chronic graft-versus host disease $(18,19)$.

The present study aimed to investigate whether HF could attenuate the progression of $\mathrm{OA}$ by preventing articular cartilage degeneration, which may add to its potential clinical application.

\section{Materials and methods}

Cell culture. The ATDC5 murine chondrogenic cell line (Riken Cell Bank, Tsukuba, Japan), were plated at a density of $1.2 \times 10^{4}$ cells $/ \mathrm{cm}^{2}$ in 6 -well plate (Corning, Inc., Corning, NY, 
USA). The cells were cultured with maintenance medium, which was Dulbecco's modified Eagle's medium/F12 (11320-033; Gibco; Thermo Fisher Scientific, Inc., Waltham, MA, USA) containing 5\% fetal bovine serum (10099-141; Gibco; Thermo Fisher Scientific, Inc.) and $1 \%$ penicillin-streptomycin (SV30010; GE Healthcare Life Sciences, Logan, UT, USA), at $37^{\circ} \mathrm{C}$ in a humidified atmosphere of $5 \% \mathrm{CO}_{2}$. The maintenance medium and it was exchanged every other day. The differentiation medium, where $1 \%$ Insulin-Transferrin-Selenium (41400-045; Gibco; Thermo Fisher Scientific, Inc.) was added to the maintenance medium, which was used when the cells became confluent. The differentiation medium was changed every other day.

Reverse transcription-quantitative polymerase chain reaction $(R T-q P C R)$. ATDC5 cells were cultured with differentiation medium for 7, 14 and 21 days. Total RNA was extracted using TRIzol reagent (15596026, Invitrogen; Thermo Fisher Scientific, Inc.) and cDNA was synthesized using PrimeScript RT Master mix (RR036A; Takara Bio, Inc., Otsu, Japan) Three or more different samples were used. qPCR reactions were performed using SYBR Fast qPCR mix (RR430A, Takara Bio, Inc.) according to the manufacturer's protocol. Amplification curves of samples were converted into relative expression values according to the curves of standard controls. Relative quantification of each gene was normalized against GAPDH. The $2^{-\triangle \Delta \mathrm{Cq}}$ method was used to calculate relative gene expression levels (20). The sequences of the following primers were used: GAPDH forward (F) 5'-AGCTTCGGC ACATATTTCATCTG-3' and reverse (R) 5'-CGTTCACTC CCATGACAAACA-3'; Col II F 5'-ACGAAGCGGCTG GCAACCTCA-3 and R 5'-CCCTCGGCCCTCATCTCT ACATCA-3; Col X F 5'-TGCCCGTGTCTGCTTTTACTG TCA-3 and R 5'-TCAAATGGGATGGGGGCACCTACT-3. Amplification cycle was set as $94^{\circ} \mathrm{C}$ for $30 \mathrm{sec}$, followed by 40 cycles at $95^{\circ} \mathrm{C}$ for $5 \mathrm{sec}, 60^{\circ} \mathrm{C}$ for $10 \mathrm{sec}$, and finally a melt curve was inserted with $65^{\circ} \mathrm{C}$ to $95^{\circ} \mathrm{C}$.

Cell Counting Kit-8 (CCK-8) analysis. The toxicity of HF on chondrocytic ATDC5 cells was observed using the CCK-8 method. After 14 days of chondrogenic differentiation, ATDC5 cells were seeded in 96-well plates with a density of $4 \times 10^{3}$ cells/well and incubated for $24 \mathrm{~h}$. The cells were treated with different concentrations of $\operatorname{HF}(0,6.25,12.5,25$, 50, 100 and $200 \mathrm{ng} / \mathrm{ml}$ ). CCK-8 (CK04; Dojindo Molecular Technologies, Inc., Kumamoto, Japan) was applied to monitor the cell viability after 24,48 and $72 \mathrm{~h}$ and the percentage of cell viability was calculated based on the absorbance at $450 \mathrm{~nm}$ after $3 \mathrm{~h}$ incubation using a microplate reader (51119300; Thermo Fisher Scientific, Inc.).

Western blot analysis. After 14 days of chondrogenic differentiation, ATDC5 cells were treated with HF (17395-31-2; Watson Noke Scientific Ltd., Kunshan, China) at different doses $0,6.25,12.5$ and $25 \mathrm{ng} / \mathrm{ml}$ for $6 \mathrm{~h}$, and were treated with $2 \mathrm{ng} / \mathrm{ml}$ rhTGF- $\beta 1$ (240-B-002; R\&D Systems, Inc., Minneapolis, MN, USA) for $30 \mathrm{~min}$ and processed for western blotting. Then the time-course experiment was performed. After 14 days of chondrogenic differentiation, ATDC5 cells were treated without $\mathrm{HF}$ for $0 \mathrm{~h}$, or with $25 \mathrm{ng} / \mathrm{ml} \mathrm{HF}$ for 4,8 and $24 \mathrm{~h}$. Then cells were treated with either $2 \mathrm{ng} / \mathrm{ml}$ rhTGF- $\beta 1$ or the reagent used to reconstitute rhTGF- $\beta 1$ (sterile $4 \mathrm{mM} \mathrm{HCl}$ containing $1 \mathrm{mg} / \mathrm{ml}$ bovine serum albumin) in an equal volume for $30 \mathrm{~min}$ and processed for western blotting. Samples $(20 \mu \mathrm{g})$ were subjected to $10 \%$ SDS-PAGE (4561083; Bio-Rad Laboratories Inc., Hercules, CA, USA) and transferred onto polyvinylidene fluoride (PVDF) membranes (ISEQ00010; Merck KGaA, Darmstadt, Germany). Membranes were blocked in 5\% bovine serum albumin (AD0023; Sangon Biotech Co., Ltd., Shanghai, China) for $1 \mathrm{~h}$, incubated with primary antibodies against Smad2/3 (1:1,000; cat. no. 3102S; Cell Signaling Technology Inc., Danvers, MA, USA), phosphorylated (p)-Smad2 (1:1,000; cat. no. 3108; Santa Cruz Biotechnology Inc., Dallas, TX, USA) and GAPDH (1:1,000; cat. no. 2118S; Cell Signaling Technology Inc.) at $4^{\circ} \mathrm{C}$ overnight, followed by incubation with secondary antibody (peroxidase-conjugated AffiniPure goat anti-rabbit IgG (H+L); 1:5,000; cat no. ZB-2301; OriGene Technologies, Inc., Beijing, China) for $2 \mathrm{~h}$. Protein was visualized using Pierce Fast Western Blot kit, enhanced chemiluminescence substrate (cat. no. 35055; Thermo Fisher Scientific, Inc.).

Experimental animals. C57BL/6 male mice (3-month old, 24-25 g, 22 in total) were purchased from Beijing Vital River Laboratory Animal Technology Co., Ltd. (Beijing, China). The mice were maintained in an animal room on a 12-h light/dark cycle with a temperature and humidity of $25 \pm 2^{\circ} \mathrm{C}$ and $55 \%$, respectively. The mice were provided with food and water ad libitum. The anterior cruciate ligament of the right knee was transected to establish a destabilized OA animal model. Sham operation was performed on independent mice by opening the knee joint capsule and suturing the incision in the right knee joint. Mice were divided into Sham, vehicle-treated anterior cruciate ligament transection (ACLT) group and HF-treated ACLT group ( $\mathrm{n}=6-8$ per group). Either $\mathrm{HF}(0.25 \mathrm{mg} / \mathrm{kg})$ or distilled water of equivalent volume $(0.2 \mathrm{ml})$ was administered by oral gavage every other day for 30 days since the second day post-operation. Mice were sacrificed at day 30 post-operatively. All animal experiment protocols were reviewed and approved by the Institutional Animal Care and Use Committee of First Affiliated Hospital of Xinjiang Medical University (Xinjiang, China).

Histochemistry, immunohistochemistry and histomorphometry. When the mice were sacrificed, the right knee joints were resected and fixed in $10 \%$ buffered formalin for $24 \mathrm{~h}$. The specimen was decalcified in $10 \%$ EDTA $(\mathrm{pH} 7.3)$ for 21 days and embedded in paraffin sagittally. Serial sections at $4-\mu \mathrm{m}$ thickness of the medial compartment of the knee joint were processed for Safranin O and Fast Green staining. The sections were incubated with primary antibodies against MMP-13 (1:100; cat. no. ab39012; Abcam; Cambridge, UK), Col X (1:100; cat. no. ab58632; Abcam), TGF- $\beta 1$ (1:100; cat. no. ab92486; Abcam) and p-Smad2/3 (1:40; cat. no. sc-11769; Santa Cruz Biotechnology Inc.) overnight at $4^{\circ} \mathrm{C}$. Subsequently a horseradish peroxidase-streptavidin detection system $(1: 1,000$; cat no. ZB-2301 and ZB-2306; OriGene Technologies, Inc., Beijing, China) was used to detect the immunoactivity at room temperature for $2 \mathrm{~h}$, followed by counterstaining with hematoxylin (OriGene Technologies, Inc.). The number of all chondrocytes and positively stained ones were calculated by eye in the entire 
articular cartilage using an optical microscope (version 510 UMA_cellSens19-Krishna-ch_00_01August 2013, Olympus Corporation, Tokyo, Japan). The Osteoarthritis Research Society International (OARSI)-Modified Mankin score was calculated as previously described by Pritzker et al (21).

Statistical analysis. Data are presented as the mean \pm standard deviation. One-way analysis of variance followed by the Least-Significant Difference post hoc test was used to determine if the difference among different groups was statistically significant. SPSS version 22.0 (IBM Corporation, Armonk, NY, USA) was used for data analysis. $\mathrm{P}<0.05$ was considered to indicate a statistically significant difference.

\section{Results}

Chondrogenic differentiation of ATDC5 cells. To examine the chondrogenic differentiation of ATDC5 cells, expression of $\mathrm{Col}$ II and Col X were analyzed by RT-qPCR. Expression of Col II increased from day 1 and peaked at day 14, indicating the early-stage differentiation of chondrocytes. Col X expression gradually increased from day 7 to day 21 , which indicated hypertrophic and calcified chondrocytes (Fig. 1).

Toxicity of HF on chondrocytic ATDC5 cells. In order to determine the appropriate dosage of HF for the subsequent in vitro study, toxicity of HF on chondrocytic ATDC5 cells was tested using CCK-8. Following incubation with HF of different concentrations for 24, 48 and $72 \mathrm{~h}$, a dose-dependent and time-dependent decrease in cell viability was observed. Cell viability was $>84 \%$ after exposure to $\mathrm{HF}$ of $6.25,12.5$ and $25 \mathrm{ng} / \mathrm{ml}$ for $24 \mathrm{~h}$. However, it was reduced to $63 \%$ following treatment with $50 \mathrm{ng} / \mathrm{ml} \mathrm{HF}$ and it was even lower in groups treated with 100 and $200 \mathrm{ng} / \mathrm{ml} \mathrm{HF}$ (Fig. 2A). From 24 to $72 \mathrm{~h}$ of exposure, $6.25,12.5$ and $25 \mathrm{ng} / \mathrm{ml} \mathrm{HF}$ had a negligible effect on the cell viability. As for HF concentrations of 50,100 and $200 \mathrm{ng} / \mathrm{ml}$, the cell viability decreased in a time-dependent manner (Fig. 2B). These findings suggested that HF of 6.25 , 12.5 and $25 \mathrm{ng} / \mathrm{ml}$ did not affect chondrocytic ATDC5 cell viability.

Halofuginone inhibited TGF- $\beta 1$ signaling in chondrocytic ATDC 5 cells. To determine whether HF has a role in regulating TGF- $\beta 1$ signaling in chondrocytic ATDC5 cells, ATDC5 cells that underwent differentiation for 14 days were used. Dose and time-dependent experiments were performed followed by western blotting. The level of $\mathrm{p}-\mathrm{Smad} 2$ protein was reduced in a does dependent manner, whereas the level of total Smad2/3 remained unchanged (Fig. 3A). Next, the present study determined the effect of HF pretreatment of chondrocytic ATDC5 cells at three different time points ( 4,8 and $24 \mathrm{~h}$ ) on the phosphorylation of Smad2 protein in response to TGF- $\beta 1$. The level of $\mathrm{p}-\mathrm{Smad} 2$ was reduced with time, whereas the level of total $S m a d 2 / 3$ remained unchanged (Fig. 3B).

Halofuginone prevented articular cartilage degeneration by inhibiting elevated TGF- $\beta 1$ signaling. To investigate whether $\mathrm{HF}$ can attenuate OA progression by way of oral gavage an ACLT mice model was established and HF was administered

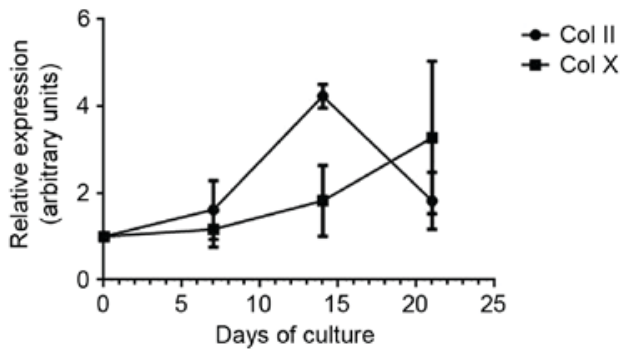

Figure 1. Chondrogenic differentiation of ATDC5 cells. ATDC5 cells were cultured at a density of $1.2 \times 10^{4}$ cells $/ \mathrm{cm}^{2}$ in 6 -well plate with differentiation medium for 7, 14 and 21 days. Expression levels of Col II and Col X were determined by reverse transcription-quantitative polymerase chain reaction. Col II, collagen type II; Col X, collagen type X.
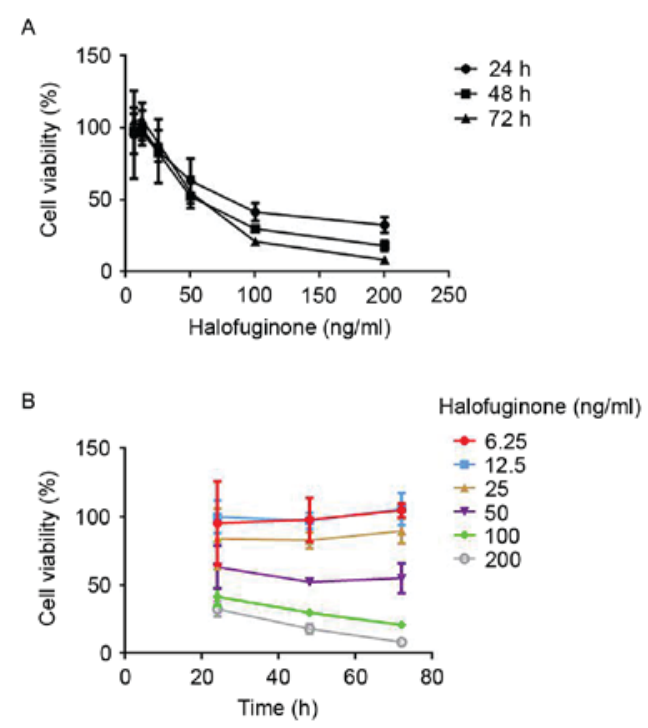

Figure 2. Toxicity of halofuginone on chondrocytic ATDC5 cells. Halofuginone induced apoptosis in a (A) dose and (B) time-dependent manner in chondrocytic ATDC5 cells.

every other day. Safranin O Fast Green staining was applied to assess the severity of articular cartilage degeneration. Deparaffinization of the slides was performed in xylene three times for $5 \mathrm{~min}$, followed by hydration in $100 \%$ alcohol twice for $5 \mathrm{~min}, 95 \%$ alcohol for $5 \mathrm{~min}$ and $80 \%$ alcohol for $5 \mathrm{~min}$. Hematoxylin was added to slides for $1 \mathrm{~min}$ prior to hydrating the slides gently in running water for $10 \mathrm{~min}$. Slides were then stained with $0.2 \%$ Fast Green for $5 \mathrm{~min}$, and then subjected to $1 \%$ acetic acid for $10 \mathrm{sec}, 0.1 \%$ Safranin O for $2 \mathrm{~min}$ and rinsing in water for $30 \mathrm{sec}$. Slides were hydrated in $95 \%$ alcohol for $15 \mathrm{sec}, 100 \%$ alcohol twice for $15 \mathrm{sec}$, followed by 3 changes in xylene prior to cover-slipping the slides. Proteoglycan loss in HF-treated group was reduced compared with the vehicle-treated group (Fig. 4A). Furthermore, the severity of articular cartilage degeneration was quantitatively evaluated using OARSI-Modified Mankin score. HF-treated group had a lower score compared with the vehicle-treated group, indicating reduced articular cartilage damage (Fig. 4B). Additionally, the expression of MMP- 13 and $\mathrm{Col} X$ was lower in the HF-treated group when compared with the vehicle-treated group (Fig. 5A and B), indicating that HF had a protective role in articular cartilage degeneration. The present study aimed 


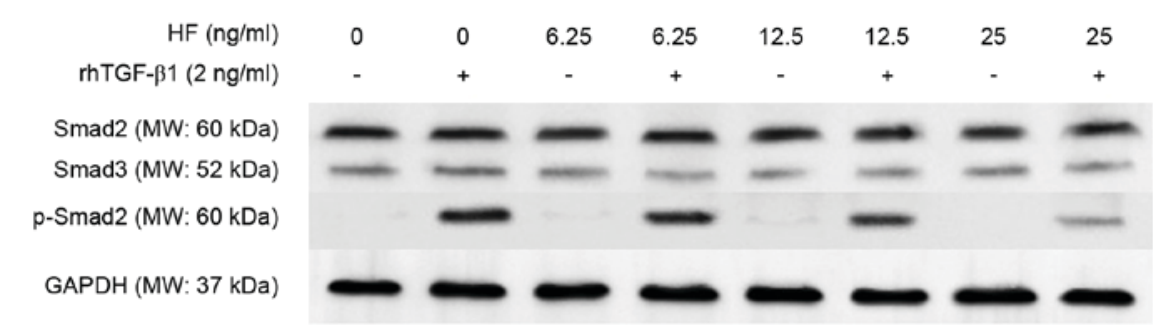

B

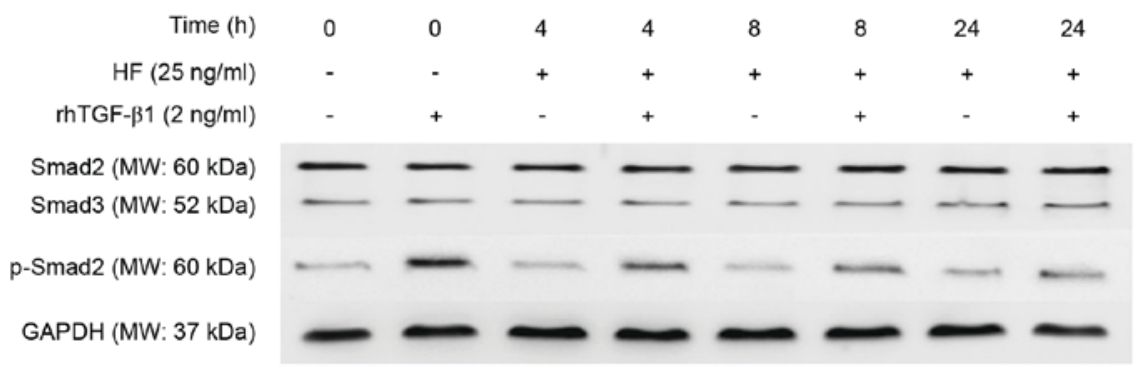

Figure 3. HF inhibited TGF- $\beta 1$ signaling in chondrocytic ATDC5 cells. Halofuginone downregulated p-Smad2 protein in a (A) dose and (B) time-dependent manner, whereas total Smad2/3 protein remained unchanged. HF, halofuginone; rhTGF- $\beta 1$, recombinant human transforming growth factor $\beta 1$; Smad2/3, SMAD family member 2/3; p-Smad2, phosphorylated-Smad2.

A
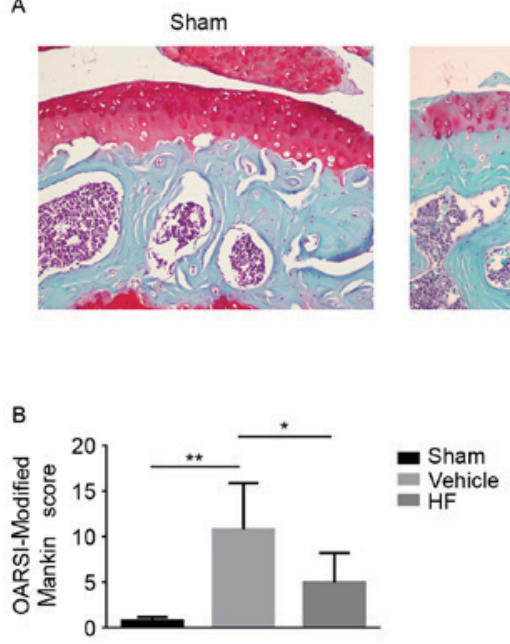

Figure 4. HF prevented articular cartilage degeneration after anterior cruciate ligament transection at 30 days. (A) Safranin $\mathrm{O}$ and Fast Green staining of sagittal sections of tibial medial compartment were performed, where proteoglycan is in red and bone is in blue. (B) OARSI-Modified Mankin score of the articular cartilage was calculated to assess the severity of cartilage degeneration quantitatively. Scale bar, $200 \mu \mathrm{m}$. " $\mathrm{P}<0.05,{ }^{* *} \mathrm{P}<0.01$. HF, halofuginone; OARSI, Osteoarthritis Research Society International.

to investigate whether TGF- $\beta 1$ had a role in the onset of OA. It was determined that the protein expression of TGF- $\beta 1$ in articular cartilage was higher in the vehicle-treated group compared with the Sham group, and HF reduced its expression (Fig. 5C). Additionally, similar results were obtained for the expression of $\mathrm{p}-\mathrm{Smad} 2 / 3$ in articular cartilage. HF-treated group had reduced expression of $\mathrm{p}-\mathrm{Smad} 2 / 3$ compared with the vehicle-treated group (Fig. 5D). Altogether, these findings suggest HF attenuated articular cartilage degeneration by inhibiting elevated TGF- $\beta 1$ signaling in articular cartilage.

\section{Discussion}

The present study transected the anterior cruciate ligament of C57BL/6 male mice to generate an unstable mechanical loading OA model. Compared with vehicle-treated group, $\mathrm{HF}$ administration attenuated OA progression by preserving articular cartilage. The underlying mechanisms of this phenomenon may be associated with its inhibitory effects on the elevated Smad2/3-dependent TGF- $\beta 1$ pathway in articular cartilage during the onset of $\mathrm{OA}$. 
A
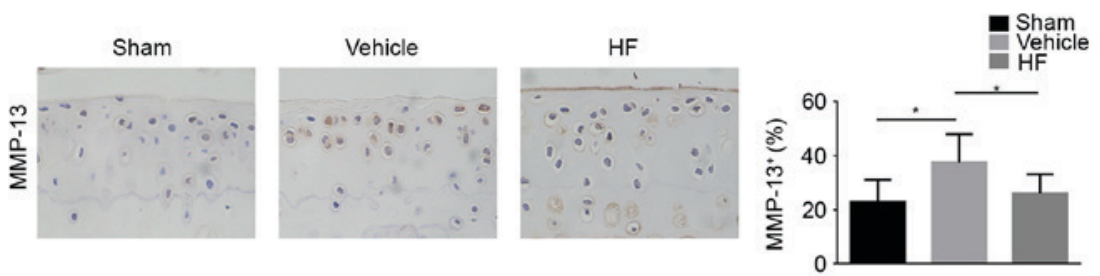

B
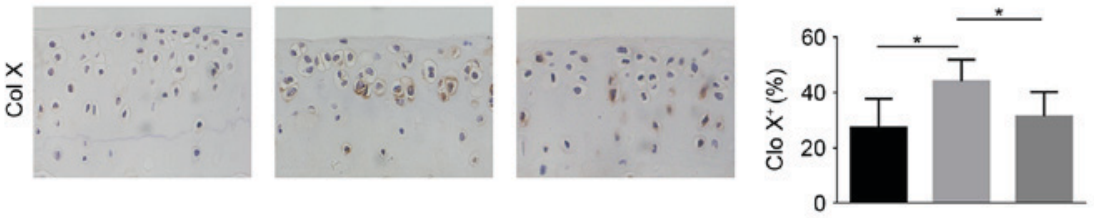

C
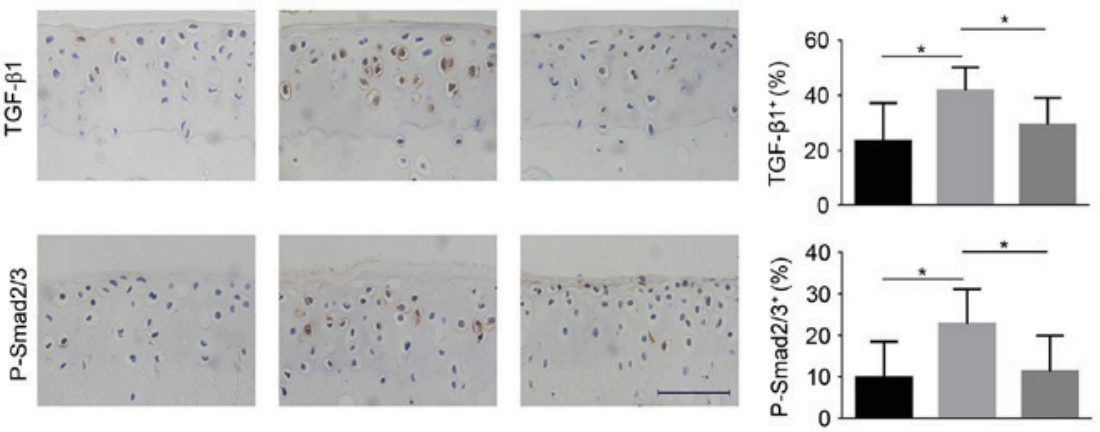

Figure 5. HF attenuated articular cartilage degeneration by inhibiting elevated TGF- $\beta 1$ signaling. Immunostaining and quantitative analysis of (A) MMP-13, (B) Col X, (C) TGF- $\beta 1$ and (D) p-Smad2/3 in articular cartilage. Scale bar, $100 \mu \mathrm{m}$. "P $<0.05$. HF, halofuginone; TGF- $\beta 1$, transforming growth factor $\beta 1$; MMP-13, matrix metallopeptidase-13; Col X, collagen type X; Smad2/3, SMAD family member 2/3; p-Smad2/3, phosphorylated-Smad2/3.

OA is a joint disorder characterized by articular cartilage degeneration, subchondral bone sclerosis, inflammation and osteophyte formation $(22,23)$. Articular cartilage has a very limited reparative capacity, which makes it important to prevent cartilage damage at early stage. Articular cartilage is highly specialized connective tissue that transfers loads during weight bearing and joint motion $(24,25)$. It primarily consists of extracellular matrix and chondrocytes. Chondrocytes are embedded in the extracellular matrix, producing a large number of collagenous extracellular matrix, including proteoglycan and Col II. Proteoglycan and Col II maintain the homeostasis and integrity of articular cartilage. During $\mathrm{OA}$, the chondrocytes become hypertrophic and synthesize proinflammatory cytokines that contribute to their own destruction $(26,27)$. Col $\mathrm{X}$ is a classic marker of hypertrophic differentiation of chondrocytes (28). MMP-13 is the primary collagenase synthesized by chondrocytes to damage aggrecan and Col II during OA. The OARSI-Modified Mankin scoring system is used to assess the severity of cartilage damage (21). The present study identified the that HF treatment reduced the expression of Col X and MMP-13 in cartilage, lowered the OARSI score when compared with the vehicle-treated group. These findings demonstrated that HF improved the homeostasis and integrity of articular cartilage.

The role of TGF- $\beta 1$ in articular cartilage is controversial. The reason for the conflicting role of TGF- $\beta 1$ in articular cartilage remains to be elucidated. It has been previously reported that TGF- $\beta 1$ is critical for the development of the knee joint. Serra et al used transgenic mice where the type II TGF- $\beta$ receptor was truncated (29). They identified the onset of early stage OA in the transgenic mice. At the age of 4 and 8 weeks, higher expression levels of $\mathrm{Col} \mathrm{X}$ and lower levels of proteoglycan were detected in the transgenic mice when compared with their wild type littermates (29). Yang et al noticed OA characteristics in Smad3-deficient mice, including loss of articular cartilage, osteophyte formation and elevated expression of Col X (30). These previous studies suggested that TGF- $\beta 1$ is important for the chondrocyte hypertrophic differentiation in immature articular cartilage. Data from in vitro studies revealed that TGF- $\beta 1$ may inhibit hypertrophic differentiation of chondrocytes through the regulation of articular cartilage matrix proteins and metalloproteases $(31,32)$. These investigations support the view that TGF- $\beta 1$ is a necessary protector against the onset of OA during the development of knee joints. Nevertheless, TGF- $\beta 1$ may also contribute to the joint destruction. High level of TGF- $\beta 1$ was detected in the articular cartilage of OA patients and mice OA models $(33,34)$. The association between elevated TGF- $\beta 1$ level and the onset of OA remains to be elucidated. The present study revealed that HF may inhibit Smad2/3-dependent TGF- $\beta 1$ signaling in chondrocytes in vitro. In adult mice, compared with sham group, elevated levels of TGF- $\beta 1$ and p-Smad $2 / 3$ were noticed in the vehicle-treated group and this was alleviated in the group treated with HF. The aforementioned findings suggested that HF prevented the cartilage damage during early-stage OA by inhibition of the elevated TGF- $\beta 1$ signaling in articular cartilage.

HF has been used in a clinical trial for the treatment of chronic graft-versus host diseases and solid tumors, and had safe therapeutic effectiveness through oral application $(35,36)$. The findings of the present study may add to its clinical application. To the best of our knowledge, the present study is the first to indicate that HF, by way of oral gavage, improved the homeostasis and integrity of articular cartilage. The underlying mechanism may be due to the 
downregulation of abnormally elevated TGF- $\beta 1$ signaling in the articular cartilage. These findings indicated that HF, administered by oral gavage and may be an effective strategy to prevent the onset of OA.

\section{Acknowledgements}

The present study was supported by grants from Major Science and Technology Projects in Xinjiang Uygur Autonomous Region (grant no. 201430123-3) and Joint Funds of the National Natural Science Foundation of China (grant no. U1503221).

\section{References}

1. McAlindon TE, Bannuru RR, Sullivan MC, Arden NK, Berenbaum F, Bierma-Zeinstra SM, Hawker GA, Henrotin Y, Hunter DJ, Kawaguchi $\mathrm{H}$, et al: OARSI guidelines for the non-surgical management of knee osteoarthritis. Osteoarthritis Cartilage 22: 363-388, 2014.

2. Vos T, Flaxman AD, Naghavi M, Lozano R, Michaud C, Ezzati M, Shibuya K, Salomon JA, Abdalla S, Aboyans V, et al: Years lived with disability (YLDs) for 1160 sequelae of 289 diseases and injuries 1990-2010: A systematic analysis for the global burden of disease study 2010. Lancet 380: 2163-2196, 2012.

3. Carr AJ, Robertsson O, Graves S, Price AJ, Arden NK, Judge A and Beard DJ: Knee replacement. Lancet 379: 1331-1340, 2012.

4. Bijlsma JW, Berenbaum F and Lafeber FP: Osteoarthritis: An update wit relevance for clinical practice. Lancet 377: 2115-2126, 2011.

5. Van den Berg WB: Osteoarthritis year 2010 in review: Pathomechanisms. Osteoarthritis Cartilage 19: 338-341, 2011.

6. de Caestecker M: The transforming growth factor-beta superfamily of receptors. Cytokine Growth Factor Rev 15: 1-11, 2004.

7. Galera P, Vivien D, Pronost S, Bonaventure J, Redini F, Loyau G and Pujol JP: Transforming growth factor-beta 1 (TGFbeta 1) up-regulation of collagen type II in primary cultures of rabbit articular chondrocytes (RAC) involves increased mRNA levels without affecting mRNA stability and procollagen processing. J Cell Physiol 153: 596-606, 1992.

8. Shen J, Li J, Wang B, Jin H, Wang M, Zhang Y, Yang Y, Im HJ, O'Keefe R and Chen D: Deletion of the transforming growth factor $\beta$ receptor type II gene in articular chondrocytes leads to a progressive osteoarthritis-like phenotype in mice. Arthritis Rheum 65: 3107-3119, 2013.

9. Massicotte F, Lajeunesse D, Benderdour M, Pelletier JP, Hilal G, Duval $\mathrm{N}$ and Martel-Pelletier J: Can altered production of interleukin-1 $\beta$, interleukin- 6 , transforming growth factor- $\beta$ and prostaglandin E (2) by isolated human subchondral osteoblasts identify two subgroups of osteoarthritic patients. Osteoarthritis Cartilage 10: 491-500, 2002.

10. Pombo-Suarez M, Castano-Oreja MT, Calaza M, Gomez-Reino J and Gonzalez A: Differential upregulation of the three transforming growth factor beta isoforms in human osteoarthritic cartilage. Ann Rheum Dis 68: 568-571, 2009.

11. Moldovan F, Pelletier JP, Hambor J, Cloutier JM and Martel-Pelletier J: Collagenase-3 (matrix metalloprotease 13) is preferentially localized in the deep layer of human arthritic cartilage in situ: In vitro mimicking effect by transforming growth factor beta. Arthritis Rheum 40: 1653-1661, 1997.

12. van Beuningen HM, van der Kraan PM, Arntz OJ and van den Berg WB: Transforming growth factor-beta 1 stimulates articular chondrocyte proteoglycan synthesis and induces osteophyte formation in the murine knee joint. Lab Invest 71 : 279-290, 1994.

13. van Beuningen HM, Glansbeek HL, van der Kraan PM and van den Berg WB: Osteoarthritis-like changes in the murine knee joint resulting from intra-articular transforming growth factor- $\beta$ injections. Osteoarthris Cartilage 8: 25-33, 2000.

14. Pines $M$ and Nagler A: Halofuginone: A novel antifibrotic therapy. Gen Pharmacol 30: 445-450, 1998.

15. Pinion JL, Bilgili SF, Eckman MK and Hess JB: The effects of halofuginone and salinomycin, alone and in combination, on live performance and skin characteristics of broilers. Poult Sci 74 391-397, 1995.
16. Pines M: Targeting TGF $\beta$ signaling to inhibit fibroblasts activation as a therapy for fibrosis and cancer: Effect of halofuginone. Expert Opin Drug Discov 3: 11-20, 2008.

17. Pines M: Halofuginone for fibrosis, regeneration and cancer in the gastrointestinal tract. World J Gastroenterol 20: 14778-14786, 2014.

18. McLoon LK: Focusing on fibrosis: Halofuginone-induced functional improvement in the mdx mouse model of Duchenne muscular dystrophy. Am J Physiol Heart Circ Physiol 294: H1505-H1507, 2008.

19. Pines M, Snyder D, Yarkoni S and Nagler A: Halofuginone to treat fibrosis in chronic graft-versus-host disease and scleroderma. Biol Blood Marrow Transplant 9: 417-425, 2003.

20. Livak KJ and Schmittgen TD: Analysis of relative gene expression data using real-time quantitative PCR and the 2(-Delta Delta C(T)) method. Methods 25: 402-408, 2001.

21. Pritzker KP, Gay S, Jimenez SA, Ostergaard K, Pelletier JP, Revell PA, Salter D and van den Berg WB: Osteoarthritis cartilage histopathology: Grading and staging. Osteoarthritis Cartilage 14: 13-29, 2006.

22. Robinson WH, Lepus CM, Wang Q, Raghu H, Mao R, Lindstrom TM and Sokolove J: Low-grade inflammation as a key mediator of the pathogenesis of osteoarthritis. Nat Rev Rheumatol 12: 580-592, 2016.

23. Goldring SR and Golding MB: Changes in the osteochondral unit during osteoarthritis: Structure, function and cartilage-bone crosstalk. Nat Rev Rheumatol 12: 632-644, 2016.

24. Lories RJ and Luyten FP: The bone-cartilage unit in osteoarthritis. Nat Rev Rheumatol 7: 43-49, 2011.

25. Madry H, van Dijk CN and Mueller-Gerbl M: The basic science of the subchondral bone. Knee Surg Sports Traumatol Arthrosc 18: 419-433, 2010.

26. Luyten FP, Lories RJ, Verschueren P, de Vlam K and Westhovens R: Contemporaty concepts of inflammation, damage and repair in rheumatic disease. Best Pract Res Clin Rheumatol 20: 829-848, 2006.

27. Goldring MB and Goldring SR: Articular cartilage and subchondral bone in the pathogenesis of osteoarthritis. Ann N Y Acad Sci 1192: 230-237, 2010

28. von der Mark K, Kirsch T, Nerlich A, Kuss A, Weseloh G, Gluckert K and Stoss H: Type X collagen synthesis in human osteoarthritic cartilage. Indication of chondrocyte hypertrophy. Arthritis Rheum 35: 806-811, 1992.

29. Serra R, Johnson M, Filvaroff EH, LaBorde J, Sheehan DM, Derynck R and Moses HL: Expression of a truncted, kinase-defective TGF-beta type II receptor in mouse skeletal tissue promotes terminal chondrocyte differentiation and osteoarthritis. J Cell Biol 139: 541-552, 1997.

30. Yang $\mathrm{X}$, Chen L, Xu X, Li C, Huang $\mathrm{C}$ and Deng CX: TGF-beta/Smad3 signals repress chondrocyte hypertrophic differentiation and are required for maintaining articular cartilage. J Cell Biol 153: 35-46, 2001.

31. Ballock RT, Heydemann A, Wakefield LM, Flanders KC, Roberts AB and Sporn MB: TGF-beta 1 prevents hypertrophy of epiphyseal chondrocytes: Regulation of gene expression for cartilage matrix proteins and metalloproteases. Dev Biol 158: 414-429, 1993.

32. Dreier R: Hypertrophic differentiation of chondrocytes in osteoarthritis: The development aspect of degenerative joint disorders. Arthritis Res Ther 12: 216, 2010

33. Schlaak JF, Pfers I, Meyer Zum Buschenfelde KH and Marker-Hermann E: Different cytokine profiles in the synovial fluid of patients with osteoarthritis, rheumatoid arthritis and seronegative spondylarthropathies. Clin Exp Rheumatol 14: 155-162, 1996.

34. Xu L, Golshirazian I, Asbury BJ and Li Y: Induction of high temperature requirement $\mathrm{A} 1$, a serine protease, by TGF-beta1 in articular chondrocytes of mouse models of OA. Histol Histopathol 29: 609-618, 2014.

35. Nagler A and Pines M: Topical treatment of cutaneous chronic graft versus host disease (cGvHD) with halofuginone: A novel inhibitor of collagen type I synthesis. Transplantation 68: 1806-1809, 1999

36. De Jonge MJ, Dumez H, Verweij J, Yarkoni S, Snyder D, Lacombe D, Marreaud S, Yamaguchi T, Punt CJ and van Oosterom A; EORTC New Drug Development Group (NDDG): Phase I and pharmacokinetic study of halofuginone, an oral quinazolinone derivative in patients with advanced solid tumours. Eur J Cancer 42: 1768-1774, 2006. 